\title{
Assessment of distribution patterns of culex disease vectors by molecular assays
}

\begin{abstract}
Study of distribution patterns of Culex pipiens forms and their sibling species Culex torrentium in Berlin and Hannover, Germany was done. The mosquitoes of the Culex genus have epidemiological significance as vectors of arboviruses and other pathogens of humans and animals. Based on molecular genetics methods it was shown that the park in Berlin in 2009 was inhabited by Culex pipiens form pipiens, while in the water container in Hannover coexistence of $C x$. pipiens form pipiens and $C x$. torrentium was noted. All females carrying sucked human blood and caught in the flats belong to Cx. pipiens form molestus. Molecular differentiation has revealed the coexistence of various Culex taxa in cities, which increases the probability of hybridization and the appearance of potential bridge vectors between birds and humans.
\end{abstract}

Keywords: Culex pipiens, Culex torrentium, PCR-RFLP, COI; ace-2,Wolbachia
Volume 6 Issue 2 - 2017

\author{
Shaikevich EV \\ NIVavilov Institute of General Genetics, Russia
}

Correspondence: Shaikevich EV, NIVavilov Institute of General Genetics, Russian Academy of Sciences, Gubkin Str., 3, Moscow II999I, Russia, Email elanashaikevich@mail.com

Received: August 15, 2017 | Published: September 21, 2017

\section{Introduction}

Culex pipiens complex taxa and sibling species $C x$. torrentium are morphologically difficult to distinguish, but differ in behaviour and ecophysiology and, accordingly, in epidemiology. With a view of their epidemiological importance, knowledge of the distribution of morphologically similar mosquitoes in nature is important for the understanding of their vector-pathogen dynamics and for their control. Mosquitoes of the genus Culex are vectors of many dangerous human and animal infections, such as filariasis, avian malaria and arboviruses - West Nile virus, Japanese encephalitis, St. Louis encephalitis, Sindbis virus and others. Beside this, people attacked by mosquitoes suffer from itching and allergic reactions. Mosquitoes of the Culex pipiens complex are of special interest. The complex includes closely related ubiquitous species. Common in Europe are $C x$. pipiens Linnaeus, 1758 and sibling species Cx. torrentium Martini, 1925. The subspecies $C x$. pipiens includes two forms, the nominate pipiens form and the molestusform. Within the temperate zone, these forms are biotopically isolated and have somewhat opposite biological features. C. pipiens form pipiens are unautogenous (able to produce of the first egg raft only after taking a blood meal), diapausing (able to enter reproductive diapause) and eurygamous (they need a large space for mating) mosquitoes, inhabit the open water bodies. While Cx. pipiens form molestus are autogenous (produce of the first egg raft without taking a blood meal), non-diapausing, stenogamous (able to mate in confined space, without swarming), and usually inhabit the underground water bodies. Cx. torrentium is morphologically and ecologically very similar to $C x$. pipiens form pipiens, the mosquitoes are unautogenous, diapausing and eurygamous.

Identification of $C x$. torrentium cause considerable problems and $C x$. torrentium is often confused with $C x$. pipiens. Unautogenous form pipiens and $C x$. torrentium inhabit the same terrestrial water basins forming 'pure' or mixed populations ${ }^{1,2}$ In W Europe, $C x$. torrentium is spread from Scandinavian Peninsula to Portugal, including Great Britain.

It is hard and often impossible to identify the species for a wild larva or imago of the Cx. pipiens complex; the morphological distinguishing traits are not obvious, the main traits being the genital structure in adults and siphonal index in larvae. However, these traits are variable, inducing problems in distinguishing between the two species. ${ }^{1,3}$ Since the species of the complex show different physiology and behavior and are of different epidemiological significance, the methods for exact identification are being actively developed basing on DNA analysis (including PCR). Several methods have been developed to distinguish between $C x$. pipiens and $C x$. torrentium. One of the methods implies different lengths of the ITS2: 400 and 350 bp in $C x$. pipiens and Cx. torrentium, respectively. ${ }^{4,5}$ Another method suggested by Smith et al. ${ }^{6}$ is based on polymorphism in intron 2 of the gene encoding acetylcholine esterase 2 (ace-2). Autogenous and anautogenous forms of $C x$. pipiens differs in microsatellite signature (Bank \& Fonseca, 2006) and with distinguished patterns of isoenzyms (Becker et al., 1999;. ${ }^{7}$ The aim of this work was to study species composition of mosquitoes from the genus Culex in Berlin and Hannover, Germany with molecular-genetics methods.

\section{Materials and methods}

Mosquito larvae were collected in September 2009 from a non-functional fountain in the park Turmstrasse, 10559 Berlin. In Hannover, mosquito larvae were collected from a container with rain water in a country house area, Prussweg, 30165 Hannover. The females carrying sucked human blood were caught in the flats of multi-store buildings (Lubecker strasse, 10, 10559 Berlin and Prussweg 6, 30165 Hannover). The larvae and the imagoes were partly dried and partly fixed with $96 \%$ alcohol for subsequent analysis. The collected larvae and imagoes were morphologically characterized as $C x$. pipiens s.l. by M.V. Fedorova and O.V. Bezzhonova.

DNA isolation, PCR and RFLP analyses were performed as described earlier. ${ }^{8}$ The results were verified by analysis of the PCR products of the gene ace- $2^{6}$ using the primers ACEpip, ACEtorr, and B1246s, suggested by the authors for Eurasia. Wolbachia infection was tested using PCR with primers wsp $81 \mathrm{~F}$ and wsp691R, complementary to a bacterial gene wsp. ${ }^{9}$

The results of the PCR-RFLP assay were confirmed by selective sequencing of the gene COI. DNA sequencing was performed using the ABI PRISM 310 sequencer and the Applera (USA) reagents kit according to the instructions of the manufacturer. The obtained sequences were analyzed using software Chromas (http://www. technelysium.com.au), polymorphism analyses were conducted in 
MEGA6. ${ }^{10}$ The sequences of the COI gene amplification products were submitted to the GenBank (accession numbers HM008665HM008672).

\section{Results and discussion}

As described earlier, ${ }^{8}$ after the PCR with primers CulexCOIF and CulexCOIR and subsequent restriction with HaeIII of the PCR products two fragments, $206 \mathrm{bp}$ and $397 \mathrm{bp}$ were obtained for the $C x$. pipiens form pipiens. The fragment of the $C x$. pipiens form molestus $C O I$ gene remained unchanged (603 bp). For mosquitoes $C x$. torrentium intraspecific variation of $\mathrm{COI}$ gene nucleotide sequence is characteristic and in recognition sequence of HaeIII endonucleases presence both adenine and guanine is possible: $60 \%$-AGCC, 30\% -GGCT (Shaikevich, 2009), therefore both variants of restriction are recorded. However, $C x$. torrentium can be identified using $B c l$ I. After $B c l$ restriction of the PCR products the DNA of $C x$. pipiens of both forms is cut in three fragments: 406bp, 118bp and 79bp. The DNA of Cx. torrentium is cut into only two fragments: $524 \mathrm{bp}$ and $79 \mathrm{bp}$.

Typical 603-bp amplification products were obtained after amplification with primers CulexCOIF and CulexCOIR for all 35 studied mosquitoes. The restriction analysis using $B c l$ I showed that all mosquitoes from Berlin belonged to $C x$. pipiens, while 4 of 14 mosquitoes from Hannover were identified as $C x$. torrentium (Table 1). The amplificates of 29 samples were cut by HaeIII into two fragments, 206 and 397 bp. In 6 samples only uncut 603-bp PCR products were present, these were obtained from all the blood-sucked females collected in the flats and from one individual collected from water container in Hannover characterized as $C x$. torrentium using $B c l$ I (Table 1). Additional analysis of the PCR products of the gene ace-2 confirmed that four individuals from Hannover population belong to $C x$. torrentium. The other studied individuals belonged to Cx. pipiens.

Table I The restriction analysis using Bcll showed that all mosquitoes from Berlin belonged to Cx. pipiens, while 4 of I4 mosquitoes from Hannover were identified as Cx. Torrentium

\begin{tabular}{|c|c|c|c|c|c|}
\hline Sample Site & Sample Number & COI/HaellI (bp) & COl/Bcll (bp) & ACE (bp) & COI GenBank AC number \\
\hline \multirow[t]{4}{*}{ Berlin, flat } & $\mathrm{BI}$ & 603 & 406, 118 and 79 & 610 & HM008670 \\
\hline & B2 & 603 & 406, 118 and 79 & 610 & HM00867I \\
\hline & B3 & 603 & 406, 118 and 79 & 610 & \\
\hline & B4 & 603 & 406, 118 and 79 & 610 & \\
\hline \multirow[t]{17}{*}{ Berlin, park } & B5 & 206 and 397 & 406, 118 and 79 & 610 & HM008668 \\
\hline & B6 & 206 and 397 & 406, 118 and 79 & 610 & HM008669 \\
\hline & B7 & 206 and 397 & 406, 118 and 79 & 610 & \\
\hline & B 8 & 206 and 397 & 406, 118 and 79 & 610 & \\
\hline & B 9 & 206 and 397 & 406, 118 and 79 & 610 & \\
\hline & B 10 & 206 and 397 & 406, II 8 and 79 & 610 & \\
\hline & B II & 206 and 397 & 406, II 18 and 79 & 610 & \\
\hline & B 12 & 206 and 397 & 406, II 18 and 79 & 610 & \\
\hline & B 13 & 206 and 397 & 406,118 and 79 & 610 & \\
\hline & B I4 & 206 and 397 & 406, 118 and 79 & 610 & \\
\hline & B I5 & 206 and 397 & 406, II 8 and 79 & 610 & \\
\hline & B 16 & 206 and 397 & 406, II 8 and 79 & 610 & \\
\hline & B 17 & 206 and 397 & 406,118 and 79 & 610 & \\
\hline & B 18 & 206 and 397 & 406, II 8 and 79 & 610 & \\
\hline & B 19 & 206 and 397 & 406,118 and 79 & 610 & \\
\hline & B 20 & 206 and 397 & 406, 118 and 79 & 610 & \\
\hline & B 21 & 206 and 397 & 406, II 18 and 79 & 610 & \\
\hline \multirow{13}{*}{$\begin{array}{l}\text { Hannover, water } \\
\text { container }\end{array}$} & $\mathrm{HI}$ & 206 and 397 & 406,118 and 79 & 610 & HM008665 \\
\hline & $\mathrm{H} 2$ & 206 and 397 & 524 and 79. & 416 & \\
\hline & $\mathrm{H} 3$ & 206 and 397 & 524 and 79. & 416 & \\
\hline & $\mathrm{H} 4$ & 206 and 397 & 406, 118 and 79 & 610 & HM008666 \\
\hline & H 5 & 206 and 397 & 406, II 18 and 79 & 610 & \\
\hline & $\mathrm{H} 6$ & 206 and 397 & 406,118 and 79 & 610 & \\
\hline & $\mathrm{H} 7$ & 603 & 524 and 79. & 416 & \\
\hline & H 8 & 206 and 397 & 406, II 18 and 79 & 610 & \\
\hline & $\mathrm{H} 9$ & 206 and 397 & 406, 118 and 79 & 610 & \\
\hline & $\mathrm{H} \mathrm{IO}$ & 206 and 397 & 524 and 79. & 416 & HM008672 \\
\hline & $\mathrm{HII}$ & 206 and 397 & 406, 118 and 79 & 610 & \\
\hline & $\mathrm{H} 12$ & 206 and 397 & 406, II 8 and 79 & 610 & \\
\hline & $\mathrm{H} \mathrm{I3}$ & 206 and 397 & 406, 118 and 79 & 610 & \\
\hline Hannover, flat & $\mathrm{H} 14$ & 603 & 406,118 and 79 & 610 & HM008667 \\
\hline
\end{tabular}


Selective sequencing of amplificates (Figure 1) has shown that the DNA of $C x$. pipiens mosquitoes of form pipiens differs from DNA of form molestus by single nucleotide substitution: position 119 of the studied fragment of the gene COI. The DNA of mosquitoes of form molestus has a characteristic substitution of Guanine within the HaeIII site (GG'CC) with Adenine (AGCC) with a loss of the respective restriction site. The DNA of $C x$. torrentium in the studied fragment differs from DNA of $C x$. pipiens by 13 nucleotide substitutions $(2,5$ $\%)$. These results are in agreement with earlier studies of the $C x$. pipiens mosquitoes in Russia. ${ }^{2,8,9}$

\begin{tabular}{|c|c|}
\hline L & $112344444 \quad 445]$ \\
\hline[ & $6161202355660]$ \\
\hline[ & $2942346125780]$ \\
\hline \#pipBerlin5 & CGTGTATTTT GTC \\
\hline \#pipBerlin6 & $\ldots \ldots \ldots \ldots$ \\
\hline \#pipHannover & $1 \ldots \ldots \ldots$ \\
\hline \#pipHannover4 & $\ldots \ldots \ldots \ldots$ \\
\hline \#pipMoscow & 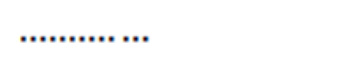 \\
\hline \#molBerlin 1 & .A............... \\
\hline \#molBerlin2 & . A............. \\
\hline \#molHannover14 & .A............. \\
\hline \#molVolgograd & .A............ \\
\hline \#torHannover10 & TACAATCCGA ACT \\
\hline \#torSPetersburg & TACAATCCGA ACT \\
\hline
\end{tabular}

Figure I Variable sites of the 5I7- bp 5'region of the COI gene.

The results show that the antropophylic females caught in multistore buildings in Berlin and Hannover belong to $\mathrm{C} x$. pipiens form molestus. The non-functional park fountain in central Berlin is inhabited by $C x$. pipiens form pipiens. Though the distance between the sampling sites is not long, populations of the form pipiens appear to exist separately, not mixing with individuals from multi-store buildings.

Of special interest is the mosquito population from the water container in Hannover, with coexistence of $C x$. pipiens form pipiens and $C x$. torrentium. Coexistence is not rare for these two species, earlier we recorded several mixed populations from Russia. $C x$. torrentium, found in Russia was not infected by Wolbachia, contrary to $C x$. pipiens, the populations of which contained up to $100 \%$ infected individuals (Vinogradova et al., 2007). Wolbachia infections in Culex pipiens complex mosquitoes in Germany also were detected. ${ }^{11}$ The PCR with primers for the gene wsp of Wolbachia showed no positive results for all four individuals of $C x$. torrentium from Hannover Though the number of the tested $C x$. torrentium mosquitoes is low, it can be suggested that this member of the $C x$. pipiens complex is not infected by these symbiotic bacteria in Germany. Probably, bacterial infection play a key role in reproductive isolation of $C x$. pipiens and $C x$. torrentium, since it is known that Wolbachia induces cytoplasmic incompatibility in Culex mosquitoes.

In conclusion, the method of species identification used in this work proved efficient for Culex pipiens mosquitoes populations from $\mathrm{N}$ Germany. Only one amplification reaction and two restriction reactions are sufficient for exact identification of both $C x$. pipiens forms, and also of $C x$. torrentium. The analysis takes 2-3 days and is considerably less expensive that the direct sequencing of the PCR products. The DNA for the PCR-RELP analysis may be isolated from an individual or any part of an individual at any stage of development. ${ }^{12}$

\section{Acknowledgements}

This work was supported by the Russian Foundation of Fundamental Research, grant N 16-04-00091. The author is grateful to Professor Ilya Zakharov-Gezehus for helpful advice and comments and to M.V. Fedorova and O.V. Bezzhonova for their help in morphological characterization of mosquitoes.

\section{Conflicts of Interset}

None.

\section{References}

1. Dahl C. Taxonomic studies on Culex pipiens and C. torentium. In: Service MW (Eds.), Biosystematics of Haematophagous Insects. 1988;37:149-172.

2. Vinogradova EB, Shaikevich EV, Ivanitsky AV. The study on the distribution of the Culex pipiens complex mosquitoes in the European part of Russia by molecular methods of their identification. Comparative Cytogenetics. 2002;1:129-138.

3. Fedorova MV, Shaikevich EV. Morphological and molecular-genetic differences between the adults of mosquitoes Culex torrentium Martini and Culex pipiens L. from Moscow Province. Entomological Review. 2007;87:127-135.

4. Miller BR, Crabtree MB, Savage HM. Phylogeny of fourteen Culex mosquito species, including the Culex pipiens complex, inferred from the internal transcribed spacers of ribosomal DNA. Insect Mol Biol. 1996;5(2):93-107.

5. Vinogradova EB, Shaikevich EV. Differentiation between the urban mosquito Culex pipiens pipiens $f$. molestus and Culex orrentium (Diptera, Culicidae) by the molecular methods Parazitologiya, Russia. 2005;39:574-576.

6. Smith JL, Fonseca DM. Rapid assays for identification of members of the Culex (Culex) pipiens complex, their hybrids, and other sibling species (Diptera: Culicidae). The American Journal of Tropical Medicine and Hygiene. 2004;70(4):339-45.

7. Weitzel T, Collado A, Joest A, et al. Genetic differentiation of populations within the Culex pipiens complex and phylogeny of related species. $J$ Am Mosq Control Assoc. 2011;25(1):6-17.

8. Shaikevich EV. PCR-RFLP of the COI gene reliably differentiates $C x$. pipiens, $C x$. pipiens $f$. molestus and Cx. torrentium of the Pipiens Complex. European Mosquito Bulletin. 2012;23:25-30.

9. Braig HR, Zhou W, Dobson SL, et al. Cloning and characterization of a gene encoding the major surface protein of the bacterial endosymbiont Wolbachia. J Bacteriol. 1988;180(9):2373-2378.

10. Tamura K, Stecher G, Peterson D, et al. MEGA6: Molecular Evolutionary Genetics Analysis version 6.0. Mol Biol Evol. 2013;30(12):2725-2729.

11. Mahilum MM, Storch V, Becker N. Molecular and electron microscopic identification of Wolbachia in Culex pipiens complex populations from the Upper Rhine Valley, Germany, and Cebu City, Philippines. J Am Mosq Control Assoc. 2003;19(3):206-210.

12. Shaikevich EV. Identification of Culex mosquitoes (Diptera, Culicidae) by the restriction assay of amplification products Meditsinskaia parazitologiia i parazitarnye bolezni, Russia. 2009;3:28-32. 